\title{
Design and Analysis of Current Mode Control of Boost Converter
}

\author{
S. Radhika ${ }^{1}$,S. Swathi ${ }^{2}$, Sarfaraz Nawaz Syed ${ }^{3}$ \\ ${ }^{1}$ Department of Electrical and Electronics Engineering, GRIET, Hyderabad, Telangana, India \\ ${ }^{2}$ Department of Electrical and Electronics Engineering, IARE, Hyderabad, Telangana, India \\ ${ }^{3}$ Department of Electrical and Electronics Engineering, RIET, Hyderabad, Telangana, India
}

\begin{abstract}
Current Mode Controller of Boost Converter is designed using standard topology and commercially available application specific Integrated circuit. Methodology of choosing components, selection of values, Design of magnetic like Inductors, Capacitors, Transformers, and Current Transformers etc has been expounded. The design is simulated on MATLAB software and tested. Mathematical Model for the above DC-DC converter is derived and a transfer function is obtained. The frequency response plot of the converter is drawn using MATLAB. Additional components for compensation based on frequency and hardware are also designed.
\end{abstract}

Keywords: Boost converter, State Space Analysis, Compensator, Current Mode Controller.

\section{Introduction}

Over the years as the portable electronics industry progressed, different requirements evolved such as increased battery lifetime, small and cheap systems, brighter, full-color displays and a demand for increased talk-time in cellular phones. An ever increasing demand from power systems has placed power consumption at a premium. To keep up with these demands engineers have worked towards developing efficient conversion techniques and also have resulted in the subsequent formal growth of an inter disciplinary field of Power Electronics.

A DC-to-DC converter is an electronic circuit which converts a source of direct current (DC) from one voltage level to another. It is also called as Chopper. It is a class of power converter. DC- DC converters are the power supply that output a fixed voltage efficiently, converting the input voltage.

The main objective of this paper is to evaluate and demonstrate different simulation tools for the simulation of switch-mode power supplies. Also the modeling process from the design engineeres point of view is considered. A current-mode controlled DC-DC boost converter in chaotic regime is chosen as an application example because it offers an up-to-date and challenging simulation problem. Although Current-mode control has been in use for over two decades, its operation and characteristics are not generally well known. Current-mode control employs an inductor current feedback loop in addition to the voltage feedback. A currentmode control converter uses the inductor current, as well as the output voltage error signal, as input signals to the PWM modulator. Current mode control is usually implemented in switching power supplies actually senses and controls peak inductor current. This gives rise to many serious problems including poor noise immunity, a need for slope compensation and peak to average current errors which the inherently low current loop gain cannot correct. Average current mode control eliminates these problems and may be used effectively to control currents other than inductor current allowing much broader range of topological applications.

This application note presents a detail modeling, design, Simulations carried out and state space model implemented in the Matlab/Simulink of current mode control of Boost converter. Based on the derived small signal modeling, the design the of compensator for the current mode control boost converter is detailed. UC3843 controller is used for the design. Simulation and hardware measurements will be shown.

\section{Basic Operation of Boost Converter}

The key principle that drives the boost converter is the tendency of an inductor to resist changes in current. When being charged it acts as a load and absorbs energy, when being discharged, it acts as an energy source. The voltage it produces during the discharge phase is related to the rate of change of current, and not to the original charging voltage, thus allowing different input and output voltages.

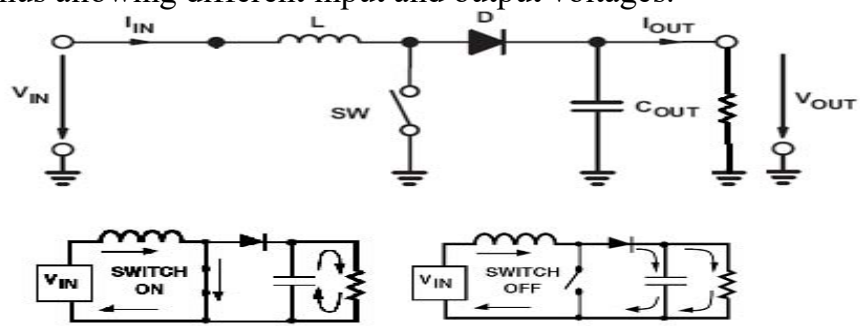

Figure 1: Boost converter when switch is ON and OFF

The above figures are the two configurations of a boost converter, depending on the state of the switch S.

The basic principle of a Boost converter consists of 2 distinct states:

1) During the ON period, Switch is made to close its contacts which results in increase of inductor current.

2) During the OFF period, Switch is made to open and thus the only path for inductor current to flow is through the fly-back diode, , $\mathrm{D}^{\mathrm{ec}}$ and the parallel combination of 


\section{International Journal of Science and Research (IJSR) \\ ISSN (Online): 2319-7064 \\ Index Copernicus Value (2013): 6.14 | Impact Factor (2014): 5.611}

capacitor and load. This enables capacitor to transfer energy gained by it during $\mathrm{ON}$ period.

During the On-state, the switch $\mathrm{S}$ is closed, which makes the input voltage $\left(V_{i}\right)$ appear across the inductor, which causes a change in current $\left(I_{L}\right)$ flowing through the inductor during a time period $(\mathrm{t})$ by the formula:

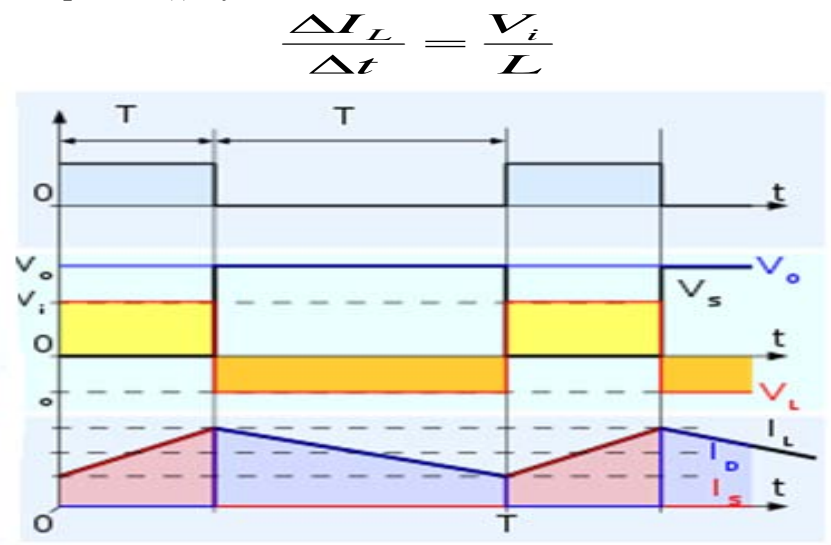

Figure 2: Waveforms of current and voltage in a boost converter

The final equation of the two modes is: $\frac{V_{O}}{V_{i}}=\frac{\boldsymbol{I}}{\boldsymbol{I}-\boldsymbol{D}}$

From the above expression it can be seen that the output voltage is always higher than the input voltage (as the duty cycle goes from 0 to 1 ), and that it increases with $\mathrm{D}$, theoretically to infinity as D approaches 1 . This is why this converter is sometimes referred to as a step-up converter.

\section{Block Diagram of Boost Converter}

\section{POWER CIRCUT}

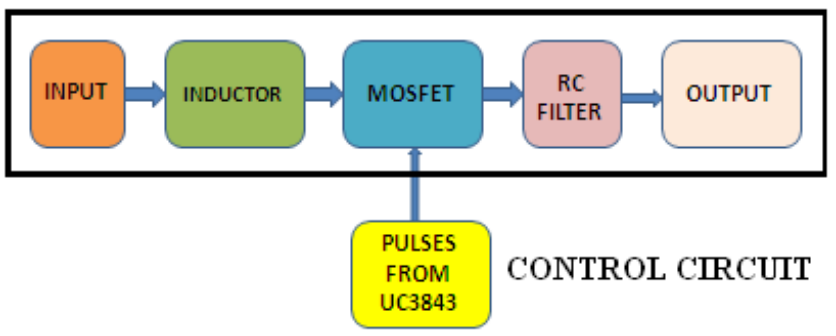

Figure 3: Block diagram of Boost converter

- The voltage source provides the input DC voltage to the switch control, and to the magnetic field storage element.

- The switch control directs the action of the switching element, while the output rectifier and filter deliver an acceptable DC voltage to the output.

\section{Duty Ratio Controlled DC-DC Converter}

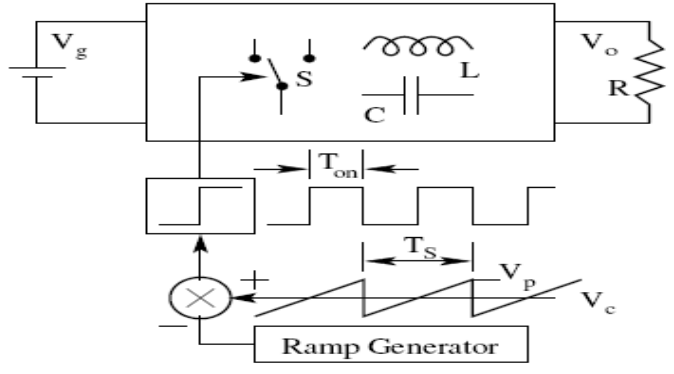

The block diagram is a duty ratio controlled converter where output voltage is taken as feedback and compared with ramp voltage which gives pulses to the MOSFET and gives required output.

\section{Design of Components of Power Circuit Power Circuit:}

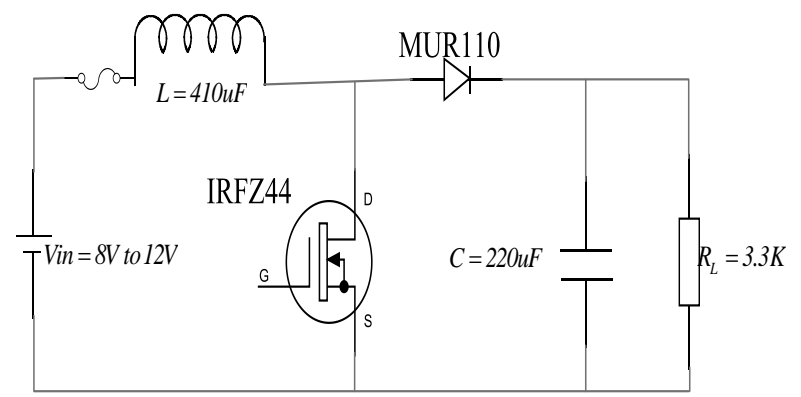

Figure 5: Boost Converter

The designing components of power circuit are inductor (Lo), Capacitor (C) and Diode (MUR110) and a MOSFET.

The following four parameters are needed to calculate the power stage:

- Input Voltage Range: VIN (min) and VIN (max)

- Nominal Output Voltage: VOUT

- Maximum Output Current: IOUT (max)

- Integrated Circuit used to build the boost converter.

This is necessary, because some parameters for the calculations have to be taken out of the datasheet.

If these parameters are known the calculation of the power stage can take place.

Table 1: Necessary Parameters Of Power Stage

\begin{tabular}{|c|c|}
\hline Necessary Parameter & Value \\
\hline Input Voltage & $12 \mathrm{~V}$ to $20 \mathrm{~V}$ \\
\hline Output Voltage & $25 \mathrm{~V}$ to $30 \mathrm{~V}$ \\
\hline Ouput Current & $0.5 \mathrm{~A}$ \\
\hline Output Power & $7.5 \mathrm{~W}$ \\
\hline Switching Frequency & $50 \mathrm{Khz}$ \\
\hline
\end{tabular}

From above parameters we can find Duty cycle, Inductor and capacitor values

$$
\begin{aligned}
& V_{\text {Wuim }}=\text { minimum input voltage } \\
& V_{\text {Wuming }}=\text { desired output voltage } \\
& V_{W P}=\text { typical input voltage } \\
& V_{\text {ONI }}=\text { desired output voltage } \\
& \Delta I_{I}=\text { estimated inductor ripple current } \\
& D=\text { duty cycle calculated } \\
& f_{g}=\text { minimum switching frequency of the converter } \\
& L=\text { selected inductor value } \\
& I_{\text {OUT }(m a x)}=\text { maximum output current of the application } \\
& \Delta V_{\text {ON }}=\text { desired output voltage ripple } \\
& C_{0 u r(m i n)}=\text { minimum output capacitance }
\end{aligned}
$$

\section{Calculation of Duty Cycle}

$$
D=1-\frac{V_{\text {WW }} \text { (min); }}{V_{\text {OUT }}}
$$

Figure 4: Duty ratio controlled dc-dc converter 


\section{International Journal of Science and Research (IJSR) \\ ISSN (Online): 2319-7064}

Index Copernicus Value (2013): 6.14 | Impact Factor (2014): 5.611

Calculation of Inductor Ripple Current:

$$
\Delta I_{L}=\frac{V_{\operatorname{dgning}} \times D}{f_{g} \times L}
$$

\section{Calculation Of Inductor:}

$$
L=\frac{V_{W} \times\left(V_{O U T}-V_{U W}\right)}{\Delta I_{L} \times f_{I} \times V_{O U T}}
$$

\section{Calculation Of Capacitor Ripple Voltage:}

$$
\Delta V_{\text {OUT }}=\frac{I_{\text {OUT }(\max )} \times D}{f_{g} \times C}
$$

\section{Capacitor Selection:}

$$
C_{\operatorname{OUr}(\min )}=\frac{I_{\operatorname{Cor}(\max )} \times(1-D)}{f_{g} \times \Delta V_{\text {ONI }}}
$$

\section{Output Voltage Setting:}

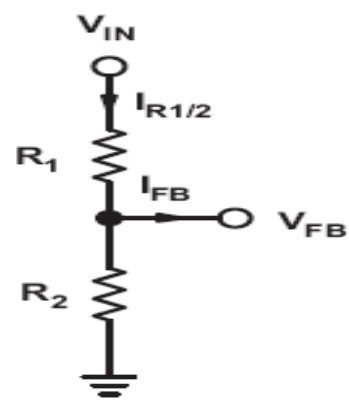

Figure 6: Resistive Divider for Setting the Output Voltage

$$
\frac{l_{\text {g1 }}}{2} \geq 100 \times I_{\mathrm{FB}}
$$

$\frac{I_{\text {II }}}{2}=$ current through the resistive divider to GND

$l_{F B}=$ feedback current

The current through the resistive divider shall be at least 100 times as big as the feedback bias current

$$
\frac{l_{\text {II }}}{2} \geq 100 \times I_{F B}
$$

This adds less than $1 \%$ inaccuracy to the voltage measurement. The current can also be a lot higher. The only disadvantage of smaller resistor values is a higher power loss in the resistive divider, but the accuracy will be a little increased.

With the above assumption, the resistors are calculated as follows:

$$
R_{2}=\frac{V_{F B}}{\frac{I_{E 1}}{2}}
$$

$$
R_{1}, R_{2} \text { = resistive divider }
$$

\section{Selection of Mosfet}

The power MOSFET has to carry about $1 \mathrm{~A}$ and block about $20 \mathrm{~V}$. The device chosen is IRFZ44.

\section{Selection of Diode}

The diode carries about $0.5 \mathrm{~A}$ average current and blocks about $20 \mathrm{~V}$ and suitable for $50 \mathrm{KHz}$ switching. The recovery time has to be better than 50ns. Therefore MUR110 is selected. Current Mode Control of Boost Converter circuit consists of circuits which are explained below

- Power circuit.

- IC controller circuit (UC3843)
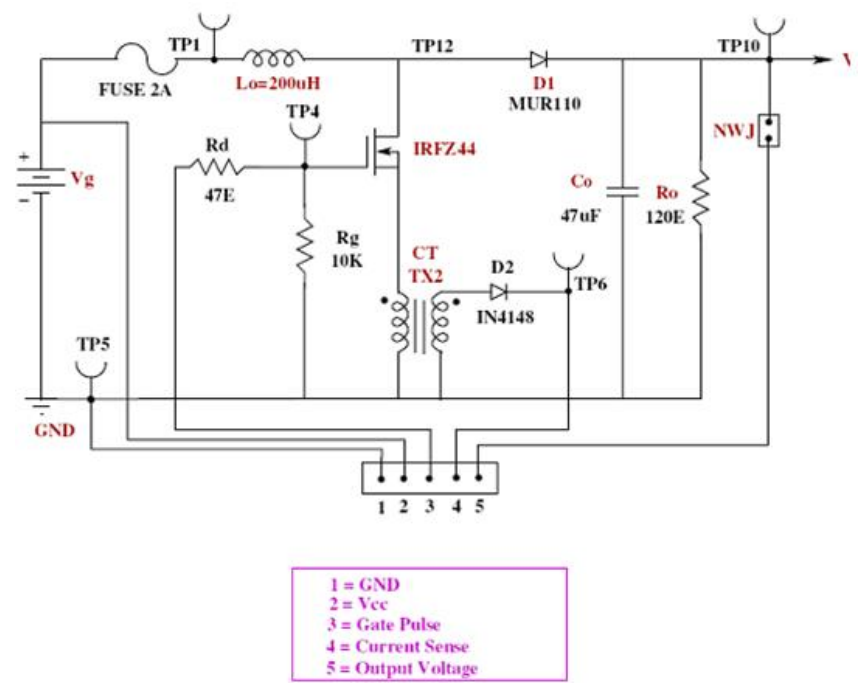

Figure 6: Power circuit of Boost converter

In the power circuit as shown in the figure (6) the input voltage given is $12 \mathrm{~V}$ to $20 \mathrm{~V}$. The diode used here is to avoid the reverse voltage. The input voltage given will be maintained across the capacitor and this voltage is given to the potential divider ( $\mathrm{R} 1=11 \mathrm{~K} \& \mathrm{R} 2=1 \mathrm{~K}$ ohms $)$.

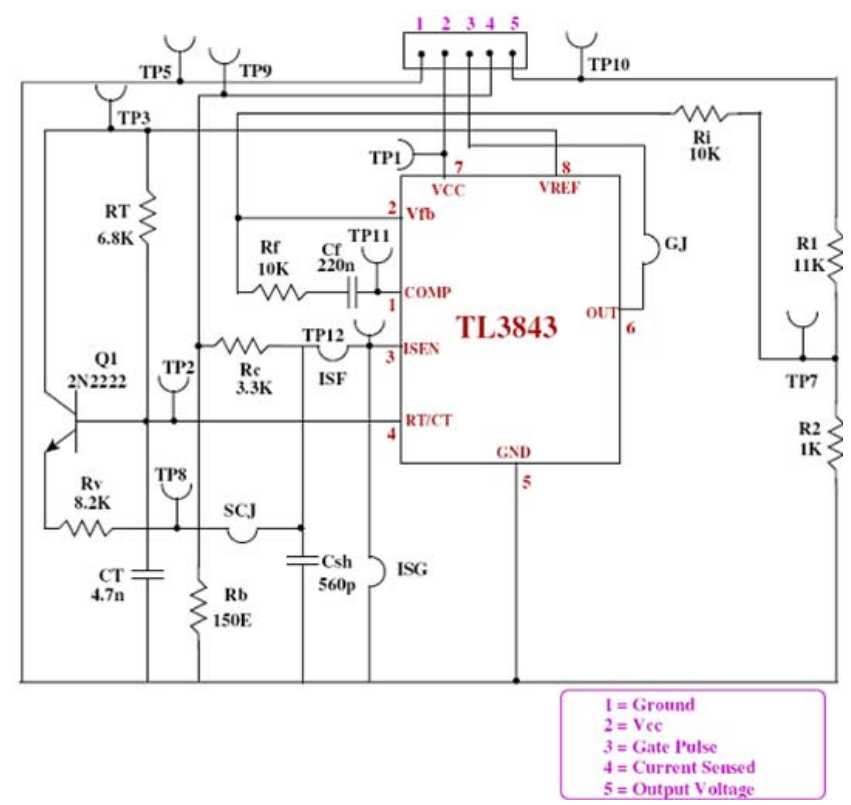

Figure 7: Control circuit of Boost converter

In the control circuit has an IC (UC3843) has an functional block diagram as shown in figure (8). The voltage across the potential divider is given to the 2 pin (voltage feedback) of the IC3843. The current through the MOSFET is sensed by the current transformer and it given to the 3 pin of the IC. The voltage feedback is compared with the reference signal of the IC through error amplifier and this output with the 


\section{International Journal of Science and Research (IJSR) \\ ISSN (Online): 2319-7064 \\ Index Copernicus Value (2013): 6.14 | Impact Factor (2014): 5.611}

output of 1 pin (compensator) is given to current sense comparator and this output is compared with the pulses produced from 4 pin (RT/CT oscillator) of the IC which generate pulses and this output pulses are given to the MOSFET.

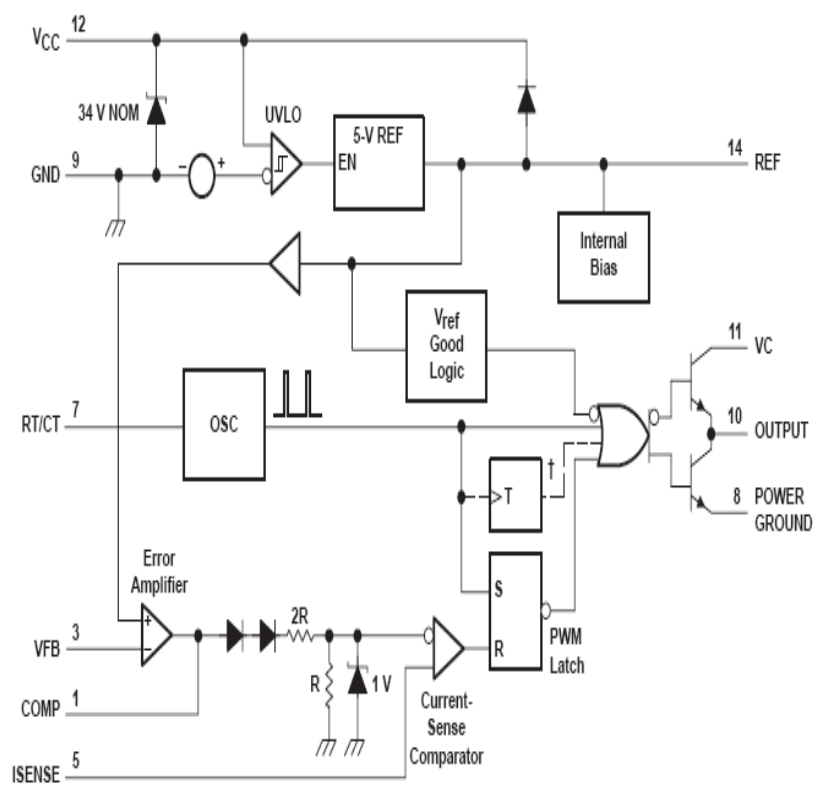

Figure 8: Functional Block Diagram of UC3843 IC

\section{State-Space Analysis}

Applying state space analysis to the basis boost converter we get the following equations depending on the state of switch (ON/OFF) in the circuit.

$$
\begin{aligned}
& X_{s}=\left|\begin{array}{cc}
0 & 0 \\
0 & -1 / C R_{L O A D}
\end{array}\right| X+\left|\begin{array}{c}
1 / L \\
0
\end{array}\right| V_{I N} \\
& X s=\left|\begin{array}{cc}
0 & -1 / L \\
1 / C & -1 / C R_{L O A D}
\end{array}\right| X+\left|\frac{1}{L}\right| V_{I N}
\end{aligned}
$$

\section{Switched Mode Boost Power Converter State-Space Average Model}

We sum $\mathrm{K}$ times the component matrix in Equation (9) plus (1-K) times the component matrix in equation (10) to provide the state space averaging equations:

$$
\begin{aligned}
& X_{S}=K\left|\begin{array}{cc}
0 & -1 / L \\
1 / C & -1 / C R_{L O A D}
\end{array}\right| X+K\left|\begin{array}{c}
1 / L \\
0
\end{array}\right| V_{I N}+ \\
& (1-K)\left|\begin{array}{cc}
0 & -1 / L \\
1 / C & -1 / C R_{L O A D}
\end{array}\right| X+(1-K)\left|\begin{array}{c}
1 / L \\
0
\end{array}\right| V_{I N}
\end{aligned}
$$

In equation (11) terms with the factor $\mathbf{K}$ arise from the first interval of the switching period, and terms with the (1-K) factor from the second interval of the switching period. The state variable $\mathbf{X}$ is now the average for the entire switching period. We distribute algebraically the duty-cycle $\mathbf{K}$ dependence as follows.

\section{Boost Power Converter Small-Signal Current-Mode Control}

The closed loop transfer function of the boost converter is given as

$$
\begin{aligned}
& G(s)=-(1-k) \frac{R_{\text {lond }}}{2} G_{\text {mbonst }} \frac{\left(\frac{1}{(1-k)^{2}} \frac{\mathbb{L}}{R_{\text {lond }}} s-1\right)}{\frac{R_{\text {load }} C}{2} s+1} \\
& G_{\text {missat }}=\frac{\Delta I_{\mathbb{I}}}{\Delta V_{G}}(13)
\end{aligned}
$$

Figure10 shows the bode plot of the current mode boost converter which is unstable. So we need to design an compensator to make the system stable

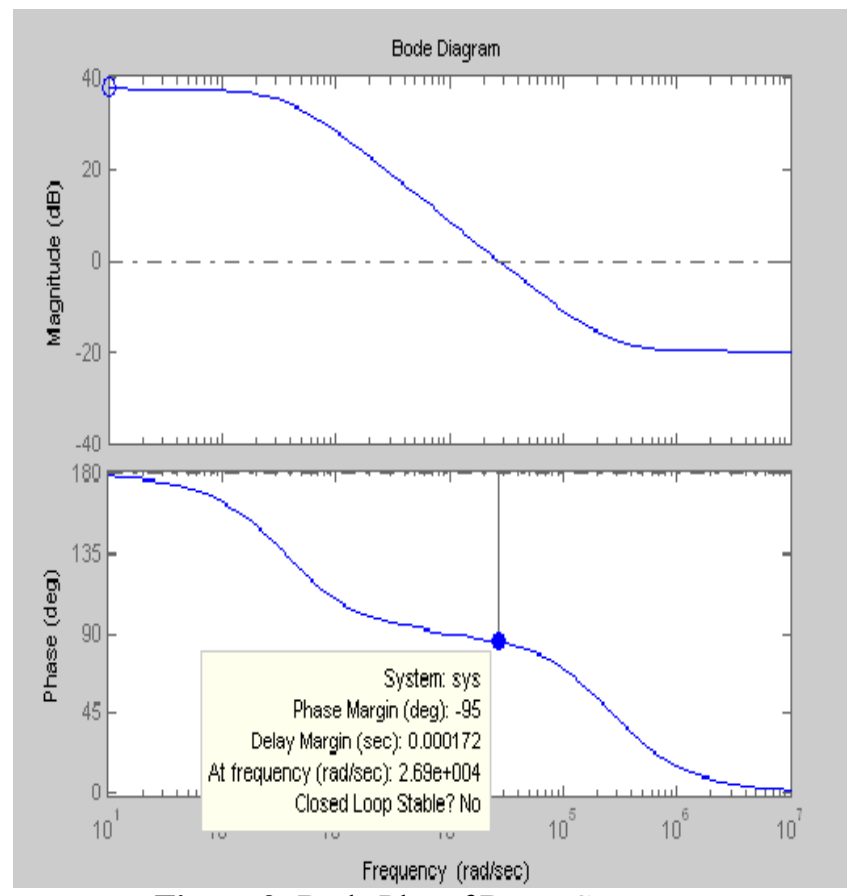

Figure 9: Bode Plot of Boost Converter

\section{Compensator Design}

Closed Loop Control:

Control Requirements:

The control specification of the converter will be in two parts.

- Steady state accuracy

- Settling time and allowed transient overshoot in the event of disturbances or command changes.

The approximate transient overshoot is related to the phase margin $(\Phi \mathrm{m})$ of the loop gain according to the Table (below) for acceptable transient overshoot, the phase margin may be taken as $45^{\circ}$. The first design step in closed loop controller design is to convert the control specification to the following. 


\section{International Journal of Science and Research (IJSR) \\ ISSN (Online): 2319-7064}

Index Copernicus Value (2013): 6.14 | Impact Factor (2014): 5.611

- Desired T(0) [to meet the steady state error]

- Desired $\omega c$ [to meet the settling time]

- Desired phase margin $\Phi \mathrm{m}$ [to meet the transient overshoot]

Table 2: Phase margin vs transient overshoot \begin{tabular}{|l|l|l|l|l|l|l|l|}
\hline Phase Margin(Degrees) & $30^{\circ}$ & $35^{\circ}$ & $40^{\circ}$ & $45^{\circ}$ & $50^{\circ}$ & $55^{\circ}$ & $60^{\circ}$ \\
\hline
\end{tabular} \begin{tabular}{|l|l|l|l|l|l|l|l|}
\hline Transient Overshoot(\%) & $37 \%$ & $30 \%$ & $35 \%$ & $16 \%$ & $9 \%$ & $5 \%$ & $1 \%$ \\
\hline
\end{tabular}

\section{Compensator Structure}

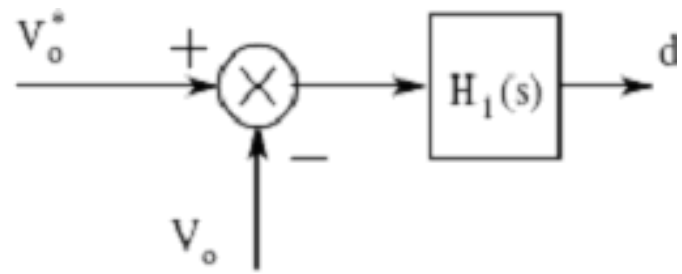

Figure 10: Structure of a closed loop controller

The requirement in the design of a closed loop controller is to identify and design a compensator $\mathrm{H}(\mathrm{s})$ such that the loop gain $T(s)[G(s) H(s)]$ satisfies the above requirements. The structure of the closed loop controller $\mathrm{H}(\mathrm{s})$ is shown in Fig (above). The stage H1(s) of the compensator achieves the desired steady state error.

In order to ensure the stability of the closed-loop system, the following conditions should be satisfied.

1) Variations in input voltage do not cause instability.

2) High gain at low frequency region.

3) Phase margin in between 45 to $60 \mathrm{deg}$.

\section{Theoretical Compensator Design:}

To meet the Steady-State Error specification we choose a PI Controller of form $\mathrm{Rf}$ and $\mathrm{Cf}$ forms the PI controller circuit.

Compensator is given by

$$
\mathrm{H}(\mathrm{s})=(\mathrm{S}+\omega \mathrm{z}) / \mathrm{S}
$$

$\omega \mathrm{z}$ is randomly choosen from Gain Crossover Frequency of Open Loop Transfer Function in order to get desired Phase margin.

$\omega \mathrm{Z}=0.017 * \omega \mathrm{cp}=454.54$

$$
\mathrm{H}(\mathrm{s})=(\mathrm{S}+454.54) / \mathrm{S}
$$

Closed Loop Transfer Function $=($ Open Loop Transfer Function * Compensator Transfer Function)

$$
T(s)=-(1-k) \frac{R_{\text {load }}}{2} G_{\text {mboost }} \frac{\left(\frac{1}{(1-k)^{2}} \frac{L}{R_{\text {lood }}} s-1\right)}{\frac{R_{\text {load }} C}{2} s+1} \times \frac{s+W_{z}}{s}
$$

Here duty cycle $\mathrm{k}$ is taken as 0.33 , Load resistance $\mathrm{R}=120 \Omega$, Inductor $\mathrm{L}=200 \mu \mathrm{H}$, Capacitor $\mathrm{C}=47 \mu \mathrm{H}$.

Substituting values in above Closed loop transfer function

$$
\begin{gathered}
T(S)=\frac{5.5865 * 10^{-3} S+1511.52}{2820 * 10^{-6} S+1} * \frac{S+454.54}{S} \\
T(S)=\frac{-0.005586 S^{2}+1509 S+6.87 e^{005}}{0.00282 S^{2}+S}
\end{gathered}
$$

\section{Practical Compensator:}

By considering, the input impedance \& the feedback impedance Zi \& Zf

For a non inverting amplifier the voltage gain is given by $\frac{z_{f}}{Z_{i}}$

Then compensator transfer function

$$
\mathrm{H}(\mathrm{s})=\frac{Z_{f}(s)}{Z_{i}(s)}
$$

After simplification, we get

$$
\frac{Z_{f}}{Z_{i}}=\frac{R_{f}+\frac{1}{C_{f} S}}{R_{i}}
$$

$T(S)=-(1-k) \frac{R_{\text {load }}}{2} G_{\text {mboost }} \frac{\left(\frac{1}{\left.(1-k)^{2} \frac{L}{R_{\text {load }}} S-1\right)}\right.}{\frac{R_{\text {loged }} C}{2} S+1} \times \frac{Z_{f}}{Z_{i}}$

After substituting the values in the above equation

$$
T(S)=\frac{-0.005586 S^{2}+1509 S+6.87 e^{005}}{0.00282 S^{2}+S}
$$

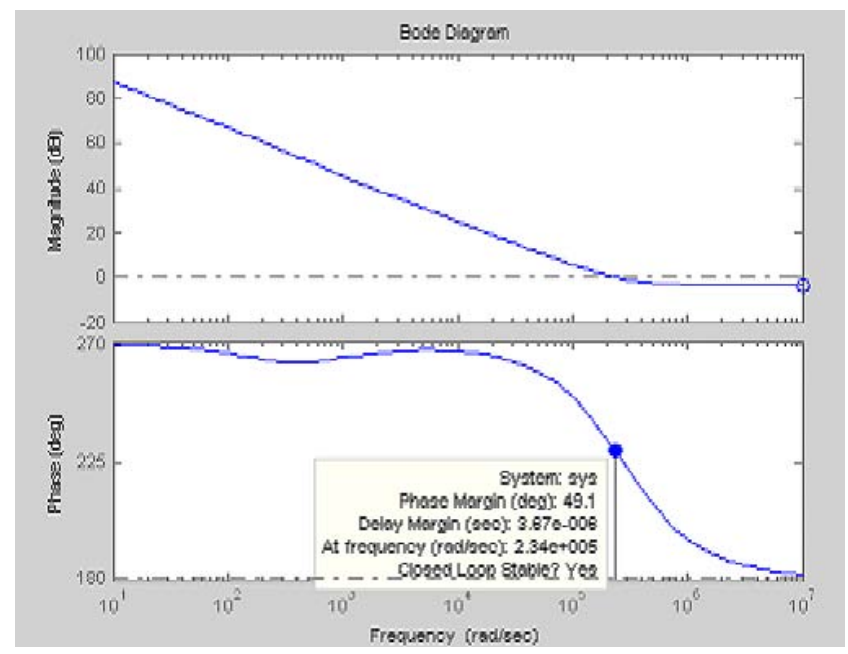

Figure 11: Bode Plot of Boost Converter with compensator

\section{Simulation and Hardware Results}

The software used in this project for simulation is MATLAB software. The circuit with compensator is designed in MATLAB and simulated. The results are shown below. 


\section{International Journal of Science and Research (IJSR) \\ ISSN (Online): 2319-7064}

Index Copernicus Value (2013): 6.14 | Impact Factor (2014): 5.611

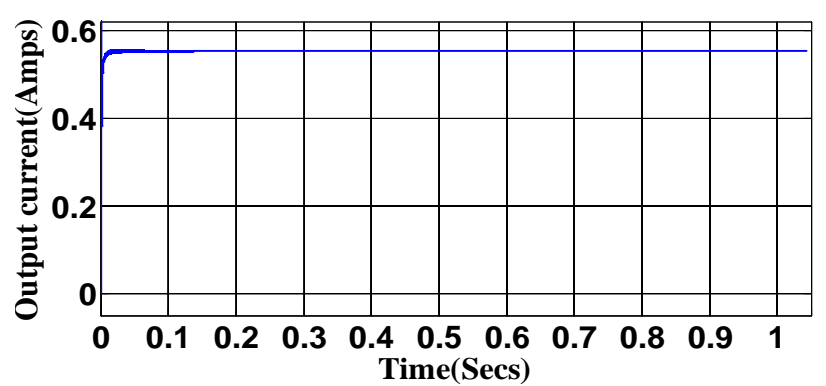

Figure 12: Output Current

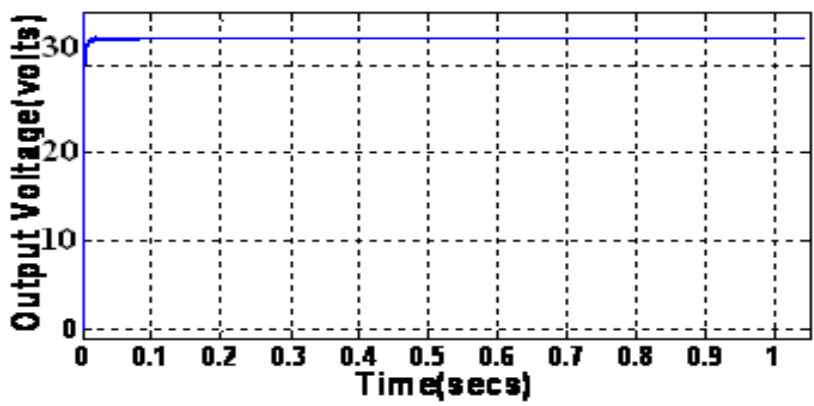

Figure 13: Output voltage

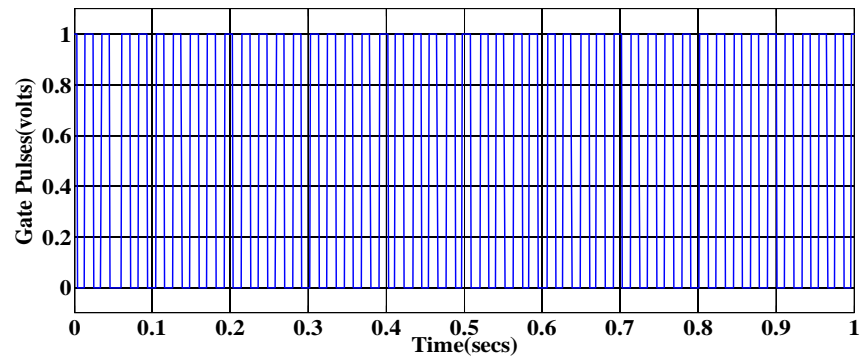

Figure 13: Gate Pulses

\section{HARDWARE DESIGN}

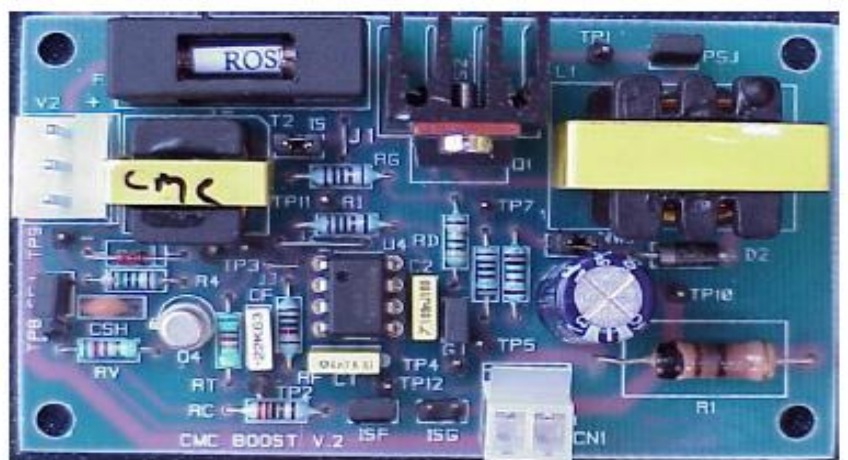

Figure 14: PCB mounted with components

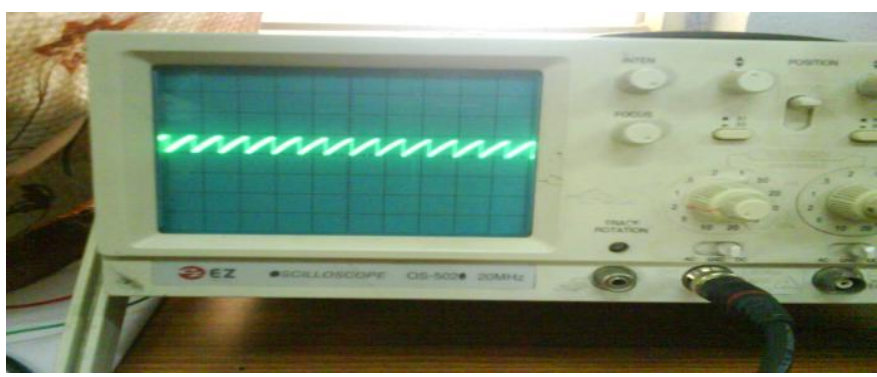

Figure 15: Ramp signal

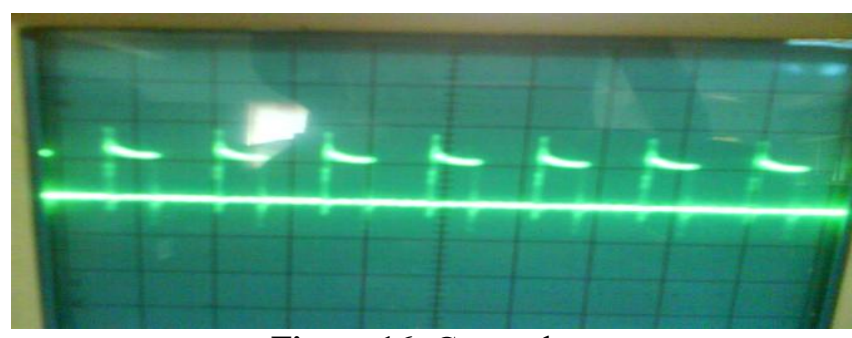

Figure 16: Gate pulses

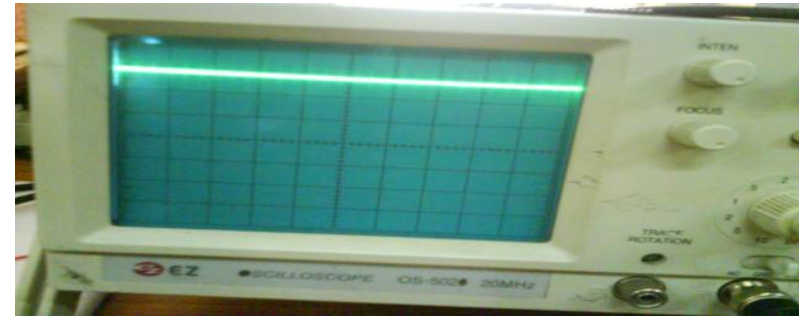

Figure 17: Output voltage

\section{Conclusion}

Current Mode Control of Boost Converter is an efficient step-up DC-DC converter used in numerous electronics devices. It is modeled and simulated using Matlab. A closed loop model is developed and used successfully for simulation. This converter has advantages like reduced hardware, high performance, less weight and accuracy. The simulation results are in line with the predictions. The same was implemented as a hardware project and an output voltage of $30 \mathrm{~V}$ was obtained with an input of $12 \mathrm{~V}-20 \mathrm{~V}$ DC supply.

\section{Future Scope}

1) Facilitating the replacement of multiple MOSFET switches in parallel with a single(less expensive) IGBT, without a compromise of the switching frequency. The design concepts developed were then extended to the design of active clamp

fly- back this can be used for many applications.

2) The active-clamp switch "on-time," might further improve converter efficiency and also "self-driven" active-clamp switches might reduce costs associated with the extra control circuitry these networks require.

\section{References}

[1] "Mathematical modeling for power dc-dc converters," in Proc. IEEE Int. Conf. POWERCON"04, Singapore, Nov 21-24, 2004, pp.323-328

[2] 'Power Electronics: Converters, Applications and Design. Mohan/undeland/Robbins.

[3] M. Pedram and Q. Wu, "Design considerations for battery-powered electronics," DAC, 1999

[4] M. K. Kazimierczuk and R. Cravens, II, "Open and closed-loop de and small-signal characteristics of PWM buck-boost converter for CCM,"J. Circuits, Syst. Comput, vol. 5, no. 3, pp. 261-3003, Sep. 1995.

[5] Application Note 1994 Modeling and Design of Current Mode Control Boost Converters. 